\title{
Foodborne Pathogenic Vibrios: Antimicrobial Resistance
}

\author{
Dipanjan Dutta ${ }^{1 * t}$, Anupam Kaushik², Dhirendra Kumar² and Satyabrata Bag ${ }^{3 * t}$ \\ ${ }^{1}$ Department of Biochemistry, Panjab University, Chandigarh, India, ${ }^{2}$ Department of Microbiology, National Centre \\ for Disease Control, New Delhi, India, ${ }^{3} 3$ B BlackBio Biotech India Limited, Bhopal, India
}

OPEN ACCESS

Edited by:

Antonio Valero,

University of Córdoba, Spain

Reviewed by:

Bhabatosh Das,

Translational Health Science and Technology Institute (THSTI),

India

Ligia Virginia Da Silva, University of Maryland Eastern Shore, United States

*Correspondence:

Dipanjan Dutta

dipanjan7@gmail.com

Satyabrata Bag

drsatyabratab@gmail.com

tThese authors have contributed equally to this work

Specialty section: This article was submitted to

Food Microbiology,

a section of the journa

Frontiers in Microbiology

Received: 06 December 2020 Accepted: 09 June 2021

Published: 30 June 2021

Citation:

Dutta D, Kaushik A, Kumar D and Bag S (2021) Foodborne Pathogenic

Vibrios: Antimicrobial Resistance.

Front. Microbiol. 12:638331. doi: 10.3389/fmicb.2021.638331
Foodborne illness caused by pathogenic Vibrios is generally associated with the consumption of raw or undercooked seafood. Fish and other seafood can be contaminated with Vibrio species, natural inhabitants of the marine, estuarine, and freshwater environment. Pathogenic Vibrios of major public health concerns are Vibrio cholerae, Vibrio parahaemolyticus, and Vibrio vulnificus. Common symptoms of foodborne Vibrio infection include watery diarrhea, stomach cramping, nausea, vomiting, fever, and chills. Administration of oral or intravenous rehydration salts solution is the mainstay for the management of cholera, and antibiotics are also used to shorten the duration of diarrhea and to limit further transmission of the disease. Currently, doxycycline, azithromycin, or ciprofloxacin are commonly used for $V$. cholerae, and doxycycline or quinolone are administered for $V$. parahaemolyticus, whereas doxycycline and a third-generation cephalosporin are recommended for $V$. vulnificus as initial treatment regimen. The emergence of antimicrobial resistance (AMR) in Vibrios is increasingly common across the globe and a decrease in the effectiveness of commonly available antibiotics poses a global threat to public health. Recent progress in comparative genomic studies suggests that the genomes of the drug-resistant Vibrios harbor mobile genetic elements like plasmids, integrating conjugative elements, superintegron, transposable elements, and insertion sequences, which are the major carriers of genetic determinants encoding antimicrobial resistance. These mobile genetic elements are highly dynamic and could potentially propagate to other bacteria through horizontal gene transfer (HGT). To combat the serious threat of rising AMR, it is crucial to develop strategies for robust surveillance, use of new/novel pharmaceuticals, and prevention of antibiotic misuse.

Keywords: foodborne Vibrio, antimicrobial resistance, seafood, drug resistant bacteria, mobile genetic elements

\section{INTRODUCTION}

Vibrio is a genus of Gram-negative bacteria under Vibrionaceae family, commonly found in aquatic environments, including marine, estuarine, and aquaculture settings. As such, they become common flora of marine life, including those consumed as seafood. So far more than 100 species of Vibrio are identified but approximately 12 species of Vibrio including Vibrio vulnificus, Vibrio parahaemolyticus, and Vibrio cholerae are the leading cause of food borne vibriosis in humans worldwide (Austin et al., 2005). Particularly, two Vibrio species viz. V. vulnificus and $V$. parahaemolyticus are the significant foodborne human pathogens, and the infections usually 
occur with the consumption of naturally contaminated raw, undercooked or cross- contaminated shellfish (oysters, crabs, and/or shrimp) and fish (sushi or sashimi) (Altekruse et al., 2000; Dechet et al., 2008). Highest number of seafood-associated bacterial gastroenteritis is caused by $V$. parahaemolyticus in many countries including United States and Asian countries (Liu et al., 2006; Scallan et al., 2011; Newton et al., 2012). In the United States, V. vulnificus is responsible for $95 \%$ of seafoodrelated deaths (Jones and Oliver, 2009). V. cholerae, the causative agent of cholera, is primarily non-saline fresh waterborne, and has been also associated with foods of terrestrial origin (Popovic et al., 1993). The illness produced by Vibrio bacteria is known as vibriosis and the symptoms include watery diarrhea, abdominal cramping, nausea, vomiting, fever, and chills (Baker-Austin et al., 2010). Usually the symptoms occur within $24 \mathrm{~h}$ of ingestion of the pathogen and last for about 3 days. Both $V$. cholerae and $V$. parahaemolyticus cause acute gastrointestinal symptoms, whereas $V$. vulnificus can cause serious and fatal infections like gastroenteritis, skin and soft tissue infections, and primary sepsis that may progress to necrotizing fasciitis and death if left untreated (Centers for Disease Control and Prevention, 2004; Bross et al., 2007).

\section{DIAGNOSIS AND TREATMENT OF FOOD BORNE VIBRIOSIS}

Laboratory diagnosis of Vibrio spp. includes enrichment of a sample of interest in alkaline peptone water, followed by culture on a selective media like thiosulfate-citrate-bile salts agar (TCBS) and/or CHROMagar Vibrio. Strains that are able to metabolize sucrose, such as $V$. cholerae will form yellow colonies on TCBS agar, whereas other pathogenic species like $V$. parahaemolyticus and $V$. vulnificus produce green colonies (Ramamurthy et al., 2020). On CHROMagar Vibrio, V. parahaemolyticus colony looks as mauve, whereas $V$. cholerae and $V$. vulnificus appears as turquoise (Passalacqua et al., 2016), then confirmed by a series of biochemical and serological tests to determine strain type. Molecular methods are currently available and widely used, including colony hybridization, polymerase chain reaction (PCR), real-time PCR, and loop-mediated isothermal amplification for species-level confirmation (Hill et al., 1991; Bej et al., 1999; Chun et al., 1999; Lyon, 2001; Campbell and Wright, 2003; Nordstrom et al., 2007). Recently cultureindependent diagnostic tests (CIDT) are increasingly used to identify enteric pathogens including Vibrios that are commonly transmitted by food due to its better sensitivity than culture and shorter turnaround time (Langley et al., 2015; Shea et al., 2016; Tarr et al., 2019).

Treatment for Vibrio spp. infection mainly depends on the causative organism: for example, administration of oral or intravenous rehydration therapy for $V$. cholerae infection and surgical debridement of infected tissues for $V$. vulnificusassociated wound infections, with antibiotic therapy for severe cholera and systemic infections (Baker-Austin et al., 2018). Antibiotic therapy reduces the duration of diarrhea, severity of infection and limit further transmission of the disease
(Lindenbaum et al., 1967). At present, azithromycin and ciprofloxacin are commonly used for $V$. cholerae, and doxycycline or quinolone for $V$. parahaemolyticus, whereas doxycycline and a third-generation cephalosporin are recommended for V. vulnificus as initial treatment regimen (Clemens et al., 2017; Baker-Austin et al., 2018). Ideally the choice of antibiotic should be based on antimicrobial susceptibility profiles of locally circulated pathogen/s.

\section{EMERGENCE OF ANTIMICROBIAL RESISTANCE IN VIBRIOS}

Vibrio spp. are usually susceptible to commonly used antibiotics of human significance (Oliver, 2006). Earlier studies had shown that the strains of $V$. vulnificus were sensitive to tetracyclines, aminoglycosides, third-generation cephalosporins, chloramphenicol, and newer fluoroquinolones (Morris and Tenney, 1985; Tang et al., 2002; Baker-Austin et al., 2008). Similarly, $V$. cholerae was effectively treated with several antibiotics like tetracycline, azithromycin and fluoroquinolones over the years (Saha et al., 2006). But antibiotic resistance has emerged and evolved in many bacterial genera including Vibrios during the past few decades due to excessive use and misuse of antibiotics in human, agriculture, and aquaculture systems (Mazel and Davies, 1999; Cabello, 2006). Despite their publichealth significance there are limited data on the effectiveness of antibiotic use in $V$. vulnificus and $V$. parahaemolyticus infections, in contrast to other enteric pathogens like Salmonella (Cabello, 2006; Han et al., 2007; Daniels, 2011). Recently, several studies have shown that $V$. vulnificus isolates became resistant to multiple antibiotics like ampicillin, tetracycline, aztreonam, streptomycin, gentamicin and tobramycin (Ji et al., 2011; Kim et al., 2011; Pan et al., 2012). Elmahdi et al. (2016) showed that most frequently observed antibiotic resistance for both $V$. parahaemolyticus and $V$. vulnificus is toward ampicillin, penicillin and tetracycline regardless of the countries. In a recent study, majority of $V$. parahaemolyticus isolates from different types of seafood in Malaysia were found to be susceptible to most antibiotics except ampicillin, cefazolin, and penicillin (Tan et al., 2020). Several other studies showed that majority of $V$. parahaemolyticus strains isolated from seafood, clinical, and environmental samples were highly resistant to multiple antibiotics like amoxicillin, ampicillin, bacitracin, carbenicillin, cefazolin, ceftazidime, cephalothin, colistin, gentamicin, penicillin, spectinomycin, and tobramycin (Zanetti et al., 2001; De Melo et al., 2011; Yano et al., 2011; Al-Othrubi et al., 2014; Elexson et al., 2014; Sudha et al., 2014).

Initially tetracycline, streptomycin and chloramphenicol were effectively used to treat cholera over the years (Reimann and Chang, 1946; Chaudhuri et al., 1950; Chakravarti et al., 1954; Carpenter et al., 1964; Uylangco et al., 1965; Saha et al., 2006). Recently, treatment failures are often observed with the recurrent emergence of antimicrobial resistant $V$. cholerae (Clemens et al., 2017). Unlike V. vulnificus and V. parahaemolyticus, more data is available on antimicrobial resistance of $V$. cholerae. Recently, Verma et al. (2019) carried out one of the largest analyses 
of antimicrobial resistance in $V$. cholerae strains $(n=443)$ isolated from the stool samples of diarrheal patients in India. In this study they selected 22 different antibiotics from nine different classes and showed that almost $99 \%$ of $V$. cholerae isolates were resistant against $\geq 2$ antibiotics, $17.2 \%$ isolates were resistant against $\geq 10$ antibiotics, and $7.5 \%$ isolates were resistant against $\geq 14$ antibiotics. The highest resistance was detected against sulfamethoxazole $(99.8 \%)$ and resistance to neomycin was observed to be lowest (4.0\%). In addition, resistance to nalidixic acid, trimethoprim and streptomycin were also very high. Another study on antibiotic susceptibility pattern of $V$. cholerae was conducted from 2000 to 2018 in Bangladesh by Parvin et al. (2020) where they have shown that there was a rapid decline of the sensitivity of $V$. cholerae to tetracycline from nearly $100 \%$ to $<6 \%$ during 2012-2017 and again increased to $76 \%$ in 2018 . Susceptibility to azithromycin and ciprofloxacin was nearly $100 \%$ throughout the study period. Dengo-Baloi et al. (2017) performed antibiotic resistance profiling in $V$. cholerae $(n=159)$ that were isolated during cholera outbreaks in Mozambique from 2012 to 2015. They showed that all the isolates were resistant to ampicillin and nalidixic acid, $13 \%$ were also resistant to azithromycin and all of them were sensitive to ciprofloxacin.

Potential source of antibiotic resistance genes for Vibrios include horizontal gene transmission from other pathogens as well as commensal gut bacteria via various mobile genetic elements (Bag et al., 2019; Verma et al., 2019; Das et al., 2020). Antibiotic resistance genes are also acquired from the environment (Cantón, 2009) including aquatic bodies like lake also served as a potential reservoir of antibiotic resistance genes (Lepuschitz et al., 2019); effluents from wastewater treatment plants are also potential reservoirs of various antibiotics resistance genes (Okoh and Igbinosa, 2010).

\section{MECHANISMS OF ANTIMICROBIAL RESISTANCE IN VIBRIOS}

Like other bacteria, the mechanisms of antibiotic resistance developed by Vibrios could be classified as (A) intrinsic (mutations originating within the organism) or (B) acquired through transfer of genetic elements during DNA replication (vertical transfer) or from different species or genera (horizontal transfer) (Figure 1).

\section{Intrinsic Resistance Mechanisms}

These are natural conditions universally found in bacterial species and are independent of antibiotic selectivity (Cox and Wright, 2013). Some of them are as follows:

\section{Limiting Uptake of a Drug Due to Permeability or Impermeability of the Outer Membrane or Cell Wall}

Bacterial outer membrane forms a major permeability barrier. Changes in the expression of outer membrane porins (deduction, loss or replacement by structure alteration) can hinder entry of antibiotics (e.g., chloramphenicol, fluoroquinolones, tetracyclines, polymixin B, erythromycin, azithromycin, and rifamycin) (Delcour, 2009). Strains expressing full length Lipopolysaccharide (LPS) have an intrinsic resistance to hydrophobic antibiotic class, such as macrolides and aminoglycosides. Other common LPS modifications [cationic substitution of phosphate groups with 4-amino-4-deoxyL-arabinose (L-Ara4N) or phosphoethanolamine (PEtN)] decrease the net negative charge of lipid A from -1.5 to -1 or from -1.5 to 0 , respectively and reduce the binding of some cationic antibiotics, such as polymyxins, leading the resistance (Delcour, 2009). Modifications of the membrane lipid barrier can reduce the fluidity of the lipopolysaccharide (LPS) and also reduce permeability of antibiotics (carbapenems, tetracycline, fluoroquinolones, aminoglycosides, and chloramphenicol).

\section{Active Drug Expulsion}

The efflux pump proteins function by excluding out the antimicrobial compounds from the bacterial cell by utilizing energy from ATP or transmembrane ion gradients (Higgins, 2007). They can be encoded from chromosome or from extrachromosomal genetic elements (Sun et al., 2014). Some examples are (a) resistance-nodulation-cell division (RND) efflux protein (extrudes ampicillin, chloramphenicol, streptomycin and tetracycline), (b) major facilitator superfamily (MFS) (pumps out tetracycline), (c) Multidrug and toxic compound extrusion (MATE) families (expel compounds derived from $\beta$-lactams, macrolides, aminoglycosides, nalidixic acid, chloramphenicol SXT scaffolds), (d) ATP-binding cassette (ABC) protein (removes $\beta$-lactams, macrolides, aminoglycosides, nalidixic acid, tetracyclines, and SXT antibiotics), (e) Small multidrug resistance (SMR) family, etc.

\section{Modification of the Target Site/Drug Target Modification}

Point mutations in the target-encoding gene result into structural change of the target molecule which can alter antibiotic-target interactions limiting to antibiotic sensitivity (Andersson and Hughes, 2010). Examples include (a) pbp gene (cell wall biosynthesis affecting $\beta$-lactam), (b) parC and gyrB gene (DNA replication and repair affecting quinolone), (c) rpsL gene (protein synthesis affecting streptomycin), (d) $k a t G, e m b B$, $m s h A$ genes (metabolic enzymes affecting Sulfamethoxazoletrimethoprim- or SXT). Post-transcriptional modification, such as methylation of specific nucleotides in $16 \mathrm{~S}$ or $23 \mathrm{~S}$ rRNA by rRNA methyltransferase can also confer resistance against several aminoglycosides and macrolides antibiotics (Holmes et al., 2016).

\section{Inactivation of a Drug}

Vibrios can either destroy antibiotic function by enzymes hydrolyzing the core drug structure or by chemical modification through transferring a chemical group to the scaffolds (Pascale and Wright, 2010). For example metallo- $\beta$-lactamase (class B) or serine- $\beta$-lactamase (classes $A, C$, and $D$ ) destroys $\beta$-lactams (Bush and Bradford, 2016). Erythromycin esterases EreA and EreB hydrolyze the macro lactone rings of macrolides, such as erythromycin except telithromycin (semisynthetic erythromycin derivative) (DrugBank database. Telithromycin, 2019. Available from: https://www.drugbank.ca/drugs/DB00976; 


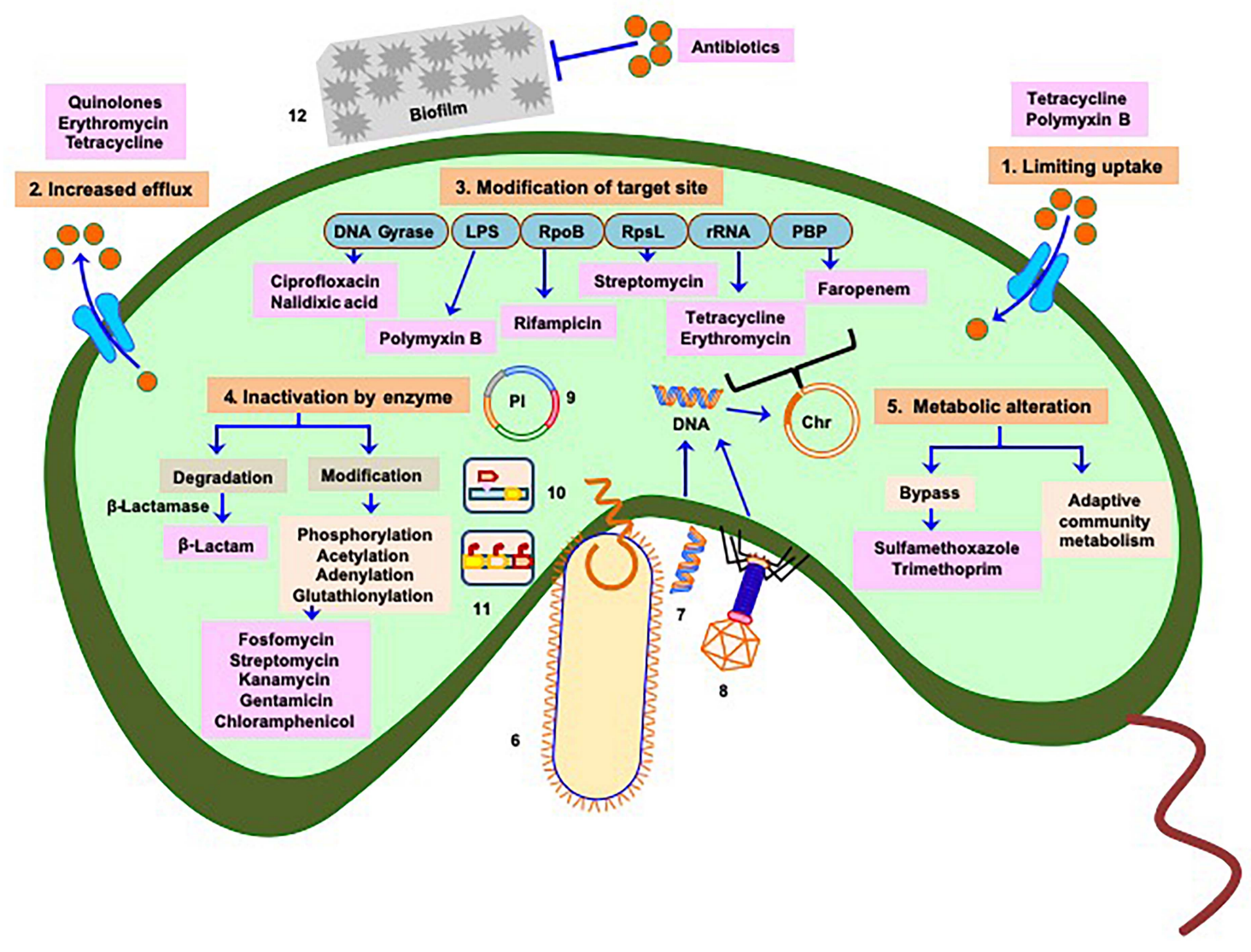

FIGURE 1 | Manifestation of antibiotic resistance mechanisms of Vibrio: multiple mechanisms (intrinsic and acquired) responsible for acquisition of drug resistance or reduced susceptibility include 1. Limiting uptake of drug, 2. Increased drug efflux, 3. Modification of drug target site (chromosome associated phenomenon), 4. Inactivation of drug by enzymatic activity, and 5. Alteration of metabolism as depicted in saffron color boxes. Routes 6,7 , and 8 represent horizontal transfer of antibiotic resistance traits (mobile genetic elements) through conjugation, transformation, and phage transduction, respectively. Plasmids containing antibiotic resistance genes are referred in 9, 10, and 11 represent transfer of mobile genetic elements via transposons and integrons respectively. 12 Physicochemical phenomenon, such as formation of biofilm also play role in acquiring antibiotic resistance. Mechanisms depicted in 6-12 imply greater and faster probability of dissemination of resistance genes to clinical strains. Light blue boxes indicate targets of different antibiotics. Red balls denote concentration of antibiotics responsible for cellular influx or efflux by transporters (cyan) or efflux proteins (cyan), respectively. Antibiotics are represented in pink boxes. PI represents plasmid, Chr represents chromosome. Based on the origin of antibiotic resistance it appears that most of the resistance mechanisms have been repurposed from intrinsic functions to the incorporation into Mobile Genetic Elements in pathogens.

Accessed: 12 January 2021). Enzymatic modification of antibiotic includes (a) O-phosphorylation (fosfomycin), (b) O-nucleotidylylation [nucleotidyl transferases (ANT)] (several aminoglycosides), (c) O-glycosylation (macrolide and rifampin), (d) $\mathrm{O}$ - and $\mathrm{N}$-acetylation (Chloramphenicol, fluoroquinolone, streptothricin, and other aminoglycosides), (e) O-ribosylation, (f) hydroxylation, etc. (D'Costa and Wright, 2009).

\section{Alternative Metabolic Pathway}

Sulfamethoxazole and trimethoprim inhibit bacterial folate synthesis pathway, but the acquisition of sul2 and $d f r A 1$ genes renders sulfamethoxazole and trimethoprim resistance, respectively. The physiology engendered tolerance, or decreased susceptibility can occur due to innate cellular property or regulatory circuit present in the organism. For example, a change in nutrient pools within a polymicrobial community may induce a change in the inherent susceptibility of certain organisms to a given antibiotic mediated by alteration in bacterial metabolism (Holmes et al., 2016).

However, based on the origin of antibiotic resistance it appears that most of the resistance mechanisms have been repurposed from intrinsic functions to the incorporation into Mobile Genetic Elements in pathogens that poses a considerable threat to human health.

\section{Acquired Resistance Mechanisms}

In the spectrum of antibiotic resistance mechanisms spontaneous mutation (appear from non-synonymous point mutation or form of insertion elements) inherited by the daughter cells through vertical transfer is relatively a slow process (Figure 1) that can modify target enzymes, alter transcription of select genes, or bypass antibiotic activity (Wyk, 2015). Recent studies showed that genetic basis of the emergence of multidrug resistant (MDR) and extensively drug resistant (ExDR) Vibrios and other enteric 
pathogenic bacteria is mainly due to horizontal gene transfer (HGT) through different types of highly dynamic mobile genetic elements, such as plasmids, integrating conjugative elements, superintegron, transposable elements, and insertion sequences (Wozniak and Waldor, 2010; Kumar et al., 2017; Verma et al., 2019) that could potentially propagate from one bacteria to other closely or distantly related bacteria. Natural competency in Vibrios allows them to uptake and chromosomally integrate, exogenous DNA coming from multidrug resistant commensal gut bacteria and other sources which ultimately leads to the emergence of drug resistant Vibrios (Meibom et al., 2005; Bag et al., 2019; Sinha-Ray et al., 2019). A novel "carryback" mechanism for inter-phylum exchange of genes is also proposed where carrier DNA sequence may be transferred from Proteobacteria to Actinobacteria via conjugative plasmid or integron and then again taken up by Proteobacteria from Actinobacteria through transformation followed by genomic integration through homologous recombination. This is then easily transferred to pathogenic bacteria which also mostly belong to the phylum Proteobacteria (Jiang et al., 2017). HGT is encouraged by the density of microbial communities and can also introduce multiple fitness factors even in the single event of acquisition. Acquiring and shedding of genetic traits encoding resistance often results more rapidly than spontaneous mutations (Wozniak and Waldor, 2010).

Bacteria can also respond to antibiotics through phenotypic variation, metabolic fluxes, programmed responses to the environment, or a systems-level effect of the bacterial community (Corona and Martinez, 2013). Enrichment of antibiotic resistance certainly depends on selective pressure, fitness cost, and dispersal (Bengtsson-Palme et al., 2018). Certain environmental hot-spot, such as sewage and wastewater treatment plants, hospital effluents, aquaculture, agricultural and slaughterhouse waste, are prime locations for genetic exchange events because of the high density of bacteria, phages, and plasmids in these regions (von Wintersdorff et al., 2016). Physicochemical phenomenon, such as formation of biofilm and quorum sensing also play the role. Biofilm formation which consists of cells, debris, proteins, polysaccharides, and extracellular DNA provides a protective covering to the bacterial community by helping the bacteria secrete enzymes which degrade antibiotics, and other antimicrobials (Singh et al., 2017). Bacterial quorum sensing induces the expression of biofilm formation. It activates several signaling pathways that cause autolysis of the cells present in the biofilm, and the extracellular DNA helps the bacteria thriving against the antibiotics (Abisado et al., 2018). Sometimes these adaptive strategies may not result in absolute resistance, they may promote tolerance in the population and allow time for the organisms to acquire extensive AMR through other mechanisms.

Primary modes of transmission of antibiotic resistance genes between different Vibrios and other bacteria are HGT pathways including conjugation, transduction, transformation and fusion (Davies and Davies, 2010; Soucy et al., 2015; Bag et al., 2019). HGT plays an important role in the acquisition of antibiotic resistance in bacteria including Vibrios. Comprehensive whole genome sequencing studies suggest that drug-resistant Vibrios harbor mobile genetic elements like plasmids, integrating conjugative elements e.g., SXT, gene cassettes, and integrons (Beaber et al., 2002; Rapa and Labbate, 2013; Partridge et al., 2018; Das et al., 2020). Interestingly, Tox R expression (by tox $R$ gene) in food borne $V$. parahaemolyticus is able to regulate the production of thermostable direct hemolysin (TDH) ( $t d h$ gene), TDH related hemolysin (TRH) (trh gene), Type III Secretion Systems T3SS1 and T3SS2 which are intrinsic factors that can cause damage from a distance even in absence of direct pathogens and hence remain ineffective in presence of antibiotics (Hubbard et al., 2016; Mala et al., 2016; Mariya Sony et al., 2021). Some clinical V. parahaemolyticus strains, however, remains pathogenic without having the mentioned virulence factors indicating the existence of putative factors and pathogenicity might be achieved with different strategies employed by different strains (Cai and Zhang, 2018). Recent study identified high prevalence (>70\%) of hemolysin $v h h$, the quorum-sensing regulator $l u x R$, chitinase chiA, and the transmembrane transcription regulator tox $R_{V h}$ in the typical host $V$. harveyi and flaC in $V$. anguillarum, wh in V. vulnificus in South China (Deng et al., 2020). Presence of tet $B /$ tet $H$ gene was identified as the predictor for the resistance against the first generation tetracycline, the most commonly used antibiotic against Vibrio spp. in marine and brackish aquaculture systems of India (Mariya Sony et al., 2021). In addition to antibiotic abuse, warming temperatures, acid-base and organic pollution can directly induce the expression of such antibiotic resistance genes and virulence genes and also affect HGT (Guijarro et al., 2015; Deng et al., 2020). A precise and critical view has been included in Table 1 which summarizes the presence of different antibiotic resistance genes identified in several Vibrio spp. including $V$. parahaemolyticus, V. cholerae, and $V$. vulnificus by various antibiotic resistance determinants specific PCR amplifications and/or whole genome sequencing.

\section{LACK OF NEW ANTIBIOTICS AND ALTERNATIVE ANTIBIOTIC THERAPY}

Lack of new antibiotics threatens global efforts to contain drug-resistant infections. There are considerable delay in the development of new class of antibiotics from the past decades. Two new classes of antimicrobials (oxazolidinones and lipopeptides) (Prokocimer et al., 2012) developed against MDR pathogens are not very efficient against Gram-negative bacteria like Vibrios (Hughes and Karlen, 2014). Other antibiotics developed are of existing classes only and 9 out of 109 candidates could only reach into phase III trials in 2012 (Hughes and Karlen, 2014). However, problems associated with antibiotic resistance are constantly evolving. Hence, cutting age techniques including adaptive laboratory evolution with antibiotic stress followed by whole-genome sequencing need frequent use to understand the evolution in real time. Apart from phenotypic characterization culture-independent metagenome and resistome analysis could provide better picture of the genetic potential of bacteria against new classes of antibiotics.

Alternative therapy using therapeutic phages targeting the pathogenic bacteria are much safer than antibiotics. Natural compounds (antimicrobial peptides from frogs, alligators, and 
TABLE 1 | Presence of antibiotic resistance genes in different Vibrio spp.

\begin{tabular}{|c|c|c|c|}
\hline Vibrio spp. & $\begin{array}{l}\text { Isolated } \\
\text { from }\end{array}$ & $\begin{array}{l}\text { Antibiotic } \\
\text { resistance genes }\end{array}$ & References \\
\hline \multirow[t]{3}{*}{ V. parahaemolyticus } & Shrimps & $\begin{array}{l}\text { class } 1 \text { integrase, } \\
\text { sul2, strB, and } \\
\text { catB3 }\end{array}$ & Beshiru et al., 2020 \\
\hline & Oysters & $\begin{array}{l}\text { qnr, strB, tet(A), } \\
\text { blaTEM }\end{array}$ & $\begin{array}{l}\text { Jeamsripong et al., } \\
2020\end{array}$ \\
\hline & Fish & $\begin{array}{l}\text { strB, blaP1, floR, } \\
\text { tetA, ermB, qnrA, } \\
\text { aac(3)-lla }\end{array}$ & Faja et al., 2019 \\
\hline \multirow[t]{3}{*}{ V. cholerae } & $\begin{array}{l}\text { Diarrheal } \\
\text { patients }\end{array}$ & $\begin{array}{l}\text { dfFrA1, sul1, } \\
\text { mphR, mrx, mphA, } \\
\text { dfrA15, merRTP, } \\
\text { FADE }\end{array}$ & Morita et al., 2020 \\
\hline & & $\begin{array}{l}\text { bla(A), bla(D), } \\
\text { ant(('), aac(3'), sh } \\
\text { ble, blandM(B), } \\
\text { aph(3'), cat, marR, } \\
\text { SXT int, strA, strB, } \\
\text { tehA, acrA, vexC }\end{array}$ & Verma et al., 2019 \\
\hline & $\begin{array}{l}\text { Stool of } \\
\text { cholera } \\
\text { patient }\end{array}$ & $\begin{array}{l}\text { gyrA (Ser83lle), } \\
\text { parC (Ser85Leu), } \\
\text { sul2, strA/strB, } \\
\text { floR, catB9, dfrA1 }\end{array}$ & Kaas et al., 2016 \\
\hline \multirow[t]{2}{*}{ V. vulnificus } & $\begin{array}{l}\text { Recreational } \\
\text { beaches }\end{array}$ & $\begin{array}{l}\text { bla }_{N D M-1}, \text { bla }_{T E M} \\
\text { bla }_{C M Y}\end{array}$ & $\begin{array}{l}\text { Oyelade et al., } \\
2018\end{array}$ \\
\hline & Fish cultures & $\begin{array}{l}\text { SXT int, strB, tetA, } \\
\text { sul2 }\end{array}$ & $\begin{array}{l}\text { García-Aljaro et al., } \\
2014\end{array}$ \\
\hline
\end{tabular}

cobras, phytochemicals, polyphenols, essential oils from plants) having antibacterial property and identification of compounds acting against bacterial toxins rather than killing the bacteria as such would be the promising approaches (Yaraksa et al., 2014; Upadhyay et al., 2015; Macwan et al., 2016). Highthroughput in silico analysis to identify novel compound/s and their mode of action on Vibrios are highly warranted. Application of non-pathogenic bacteria from the natural flora (probiotic therapy) (Bdellovibrio bacteriovorus, Micavibrio aeruginosavorus, Ruminococcus obeum) have been found to attenuate the disease progression (Dwidar et al., 2012). Several antivirulent strategies, such as targeting bacterial adhesion, colonization, toxin production, and quorum sensing have been developed recently by chemical compounds, and natural compounds, such as phytochemicals and nanotechnology. Examples are Virstatin (4-[N-(1,8-naphthalimide)]-n-butyric acid) (block ToxT gene); 6- Gingerol and Zinc oxide nanoparticles (prevent interaction of cholera toxin with GM1 receptor); Lactoferrin in milk has antiadhesive activity by iron chelation (Ammons and Copié, 2013). Many metal oxides, polymer nanoparticles, metal nanoparticle-DNA aptamer conjugates, Flash NanoPrecipitation of water-dispersible CAI-1 autoinducer nanocarriers have been identified to have potent antibiofilm activity. Other strategies, such as oral vaccines [Dukoral (SBL Vaccines), Shanchol (Shantha Biotech, India), Euvichol (EuBiologic Co., Ltd., Chuncheon, South Korea), and mORCVAX (Vabiotech, Hanoi, Vietnam)] are widely used against cholera to confer moderate protection, but, herd immunity can multiply the effectiveness (Martin et al., 2014). Vaccines in combination with other preventive measures, such as regulation of needless use of antibiotics, WASH (Water, sanitation, and hygiene) program, proper cooking of foods (especially seafoods), keeping food away from contaminants, washing fruits and vegetables before cooking may help in reducing the antimicrobial use and thereby decrease the chances of developing AMR. Communal participation to tackle the challenge of AMR is also very critical.

\section{FUTURE DIRECTIONS AND CONCLUDING REMARKS}

Vibrios, the autochthonous inhabitant of aquatic environment, upon infection seeded into the environment where it acquires and transmits new genes, including antibiotic resistance. To prevent and control the spread of food borne vibriosis, the consumers should avoid eating raw or undercooked seafoods as they are the significant source of potentially pathogenic Vibrios. Several decontamination methods like high pressure processing technique and the use of different effective chemicals are available to effectively reduce the number of Vibrios without compromising the food-value of raw and finished food products (Mata et al., 1994; de Castillo et al., 1998; Berlin et al., 1999; Cook, 2003).

Misuse and overuse of antibiotics leads to the emergence of antimicrobial resistance in microorganisms including Vibrios and it is increasing across the globe that poses a global threat to public health. It requires urgent multisectoral action in order to achieve the goals of sustainable development. Because of widespread resistance to antibiotics, robust surveillance is needed to detect changing sensitivity patterns for determining the drug of choice for treating Vibrio infections. It is crucial to determine the mechanisms of virulence and the consequences of host-pathogen interactions from both the pathogen and host perspective. With cutting age techniques identification of bacterial virulence along with knowledge of genomes should be used to identify novel targets to design and develop multidisciplinary and novel treatments.

All countries should actively participate in the Global Antimicrobial Resistance Surveillance System (GLASS) which was launched by the World Health Organization in 2015 to support the global action plan on antimicrobial resistance (World Health Organization, 2015). Although several programs have been implemented in countries, such as EU, United States, Japan, Sweden, and Denmark and recently in countries, such as India, China, Thailand, and South Africa (Founou et al., 2016), a consolidated action plan is warranted to take proactive steps toward prevention of food borne pathogen's spread (Centers for Disease Control and Prevention, 2018).

To tackle the infections caused by multidrug resistant and extensive drug resistant Vibrios and other bacteria there is an urgent need to develop new antibiotics or modern-day alternative therapeutics but unfortunately this has slowed considerably in past decades. During this health crisis, the infections can 
be prevented if we all have better hygiene, access to clean water and sanitation, infection control in healthcare facilities and vaccination, which could help us to reduce the need for antibiotics. In the age of multi-drug resistance, the universal decline in the effectiveness of antibiotics has generated renewed interest in revisiting the practice of phage therapy by cocktail treatment (Jun et al., 2014), usage of quorum sensing inhibitors, and anti-secretory drugs and more research efforts are essential on probiotic therapy (Hsiao et al., 2014) and re-sensitization of drug resistant pathogens (Sun et al., 2020).

\section{REFERENCES}

Abisado, R. G., Benomar, S., Klaus J. R., Dandekar, A. A., Chandler, J. R. (2018). Bacterial quorum sensing and microbial community interactions. mBio 9:e001749-18.

Al-Othrubi, S. M., Kqueen, C. Y., Mirhosseini, H., Hadi, Y. A., and Radu, S. (2014). Antibiotic resistance of Vibrio parahaemolyticus isolated from cockles and shrimp sea food marketed in Selangor, Malaysia. Clin. Microbial. 3, 148-154. doi: 10.4172/2327-5073.1000148

Altekruse, S. F., Bishop, R.D., Baldy, L. M., Thompson, S. G., Wilson, S. A., Ray, B. J., et al. (2000). Vibrio gastroenteritis in the US Gulf of Mexico region: the role of raw oysters. Epidemiol. Infect. 124, 489-495. doi: 10.1017/ s0950268899003714

Ammons, M.C., and Copie', V. (2013). Mini-review: lactoferrin: a bioinspired, anti-biofilm therapeutic. Biofouling. 29, 443-455. doi: 10.1080/08927014.2013. 773317

Andersson, D. I., and Hughes, D. (2010). Antibiotic resistance and its cost: is it possible to reverse resistance?. Nat. Rev. Microbiol. 8, 260-271. doi: 10.1038/ nrmicro2319

Austin B., Austin D., Sutherland R., Thompson F., and Swings J. (2005). Pathogenicity of vibrios to rainbow trout (Oncorhynchus mykiss, Walbaum) and Artemianauplii. Environ. Microbiol. 7, 1488-1495. doi: 10.1111/j.14622920.2005.00847.x

Bag, S., Ghosh, T. S., Banerjee, S., Mehta, O., Verma, J., Dayal, M., et al. (2019). Molecular insights into antimicrobial resistance traits of commensal human gut microbiota. Microb. Ecol. 77, 546-557. doi: 10.1007/s00248-018-1228-7

Baker-Austin, C., McArthur, J. V., Tuckfield, R. C., Najarro, M., Lindell, A. H., Gooch J et al. (2008). Antibiotic resistance in the shellfish pathogen Vibrio parahaemolyticus isolated from the coastal water and sediment of Georgia and South Carolina, USA. J. Food Prot. 71, 2552-2558. doi: 10.4315/0362-028x-71. 12.2552

Baker-Austin, C., Oliver, J. D., Alam, M., Ali, A., Waldor, M. K., Qadri, F., et al. (2018). Vibrio spp. Infections. Nat. Rev. Dis. Primers. 4:8. doi: 10.1038/s41572018-0005-8

Baker-Austin, C., Stockley, L., Rangdale, R., and Martinez-Urtaza, J. (2010). Environmental occurrence and clinical impact of Vibrio vulnificus and Vibrio parahaemolyticus: A European perspective. Environ. Microbiol. Rep. 2, 7-18. doi: 10.1111/j.1758-2229.2009.00096.x

Beaber, J. W., Hochhut, B., and Waldor, M. K. (2002). Genomic and functional analyses of SXT, an integrating antibiotic resistance gene transfer element derived from Vibrio cholerae. J. Bacteriol. 184, 4259-4269. doi: 10.1128/jb.184. 15.4259-4269.2002

Bej AK, Patterson DP, Brasher CW, Vickery MC, Jones DD, Kaysner CA., et al. (1999). Detection of total and hemolysin producing Vibrio parahaemolyticus in shellfish using multiplex PCR amplification of tl, tdh, and trh. J. Microbiol. Methods. 36, 215-225. doi: 10.1016/s0167-7012(99)00037-8

Bengtsson-Palme, J., Kristiansson, E., and Larsson, D. G. J. (2018). Environmental factors influencing the development and spread of antibiotic resistance. FEMS Microbiol. Rev. 42, 68-80. doi: 10.1093/femsre/fux053

Berlin, D. L., Herson, D. S., Hicks, D. T., and Hoover, D. G. (1999). Response of pathogenic Vibrio species to high hydrostatic pressure. Appl. Environ. Microbiol. 65, 2776-2780. doi: 10.1128/aem.65.6.2776-2780 .1999

\section{AUTHOR CONTRIBUTIONS}

DD and SB conceptualized and wrote the manuscript. AK and DK edited the review. All authors read and approved the review.

\section{FUNDING}

DD's research was supported by a project grant of Indian Council of Medical Research (Grant ID: 2019-0857).

Beshiru, A., Okareh, O. T., Okoh, A. I., and Igbinosa, E. O. (2020). Detection of antibiotic resistance and virulence genes of Vibrio strains isolated from readyto-eat shrimps in delta and Edo states, Nigeria. J. Appl. Microbiol. 129, 17-36. doi: 10.1111/jam. 14590

Bross, M. H., Soch, K., Morales, R., and Mitchell, R. B. (2007). Vibrio vulnificus infection: diagnosis and treatment. Am. Fam. Physician. 76, 539-544.

Bush, K., and Bradford, P. A. (2016). Beta-lactams and beta-lactamase inhibitors: An overview. Cold Spring Harb. Perspect. Med. 6:a025247. doi: 10.1101/ cshperspect.a025247

Cabello, F. C. (2006). Heavy use of prophylactic antibiotics in aquaculture: a growing problem for human and animal health and for the environment. Environ. Microbiol. 8, 1137-1144. doi: 10.1111/j.1462-2920.2006.01054.x

Cai, Q., and Zhang, Y. (2018). Structure, function and regulation of the thermostable direct hemolysin (TDH) in pandemic Vibrio parahaemolyticus. Microb. Pathog. 123, 242-245. doi: 10.1016/j.micpath.2018.07.021

Campbell, M. S., and Wright, A. C. (2003). Real-time PCR analysis of Vibrio vulnificus from oysters. Appl. Environ. Microbiol. 69, 7137-7144. doi: 10.1128/ AEM.69.12.7137-7144.2003

Cantón, R. (2009). Antibiotic resistance genes from the environment: a perspective through newly identified antibiotic resistance mechanisms in the clinical setting. Clin. Microbiol. Infect. 15, 20-25. doi: 10.1111/j.1469-0691.2008. 02679.x

Carpenter, C. C., Sack, R. B., Mondal, A., and Mitra, P. P. (1964). Tetracycline therapy in cholera. J. Indian Med. Assoc. 43, 309-312.

Centers for Disease Control and Prevention (2018). The Core Elements Of Human Antibiotic Stewardship Programs In Resource -Limited Settings: National And Hospital Levels. Atlanta, GA: US Department of Health and Human Services.

Centers for Disease Control and Prevention. (2004). Summary of human Vibrio isolates reported to CDC, 2004. Available Online at: https://www.cdc.gov/ nationalsurveillance/pdfs/vibrio2004.pdf [Accessed 26 November 2020].

Chakravarti, H. S., Mondal, A., Mukherjee, A. M., and Pal, N. G. (1954). Further observations on intravenous chloramphenicol in cholera. J. Indian. Med. Assoc. 23, 331-332.

Chaudhuri, R. N., Ghosal, S., and Rai Chaudhuri, M. N. (1950). Chloromycetin in the treatment of cholera. Ind. Med. Gaz. 85, 398-400.

Chun, J., Huq, A., and Colwell, R. R. (1999). Analysis of 16S-23S rRNA intergenic spacer regions of Vibrio cholerae and Vibrio mimicus. Appl. Environ. Microbiol. 65, 2202-2208.

Clemens, J. D., Nair, G. B., Ahmed, T., Qadri, F., and Holmgren, J. (2017). Cholera. Lancet 390, 1539-1549. doi: 10.1016/S0140-6736(17)30559-7

Cook, D. W. (2003). Sensitivity of Vibrio species in phosphate-buffered saline and in oysters to high-pressure processing. J. Food Prot. 66, 2276-2282. doi: $10.4315 / 0362-028 \mathrm{x}-66.12 .2276$

Corona, F., and Martinez, J. L. (2013). Phenotypic resistance to antibiotics. Antibiotics (Basel) 2, 237-255.doi: < PMID < PMID:NOPMID $</$ PMID $<$

Cox, G., and Wright, G. D. (2013). Intrinsic antibiotic resistance: Mechanisms, origins, challenges and solutions. Inter. J. Med. Microbiol. 303, 287-292. doi: 10.1016/j.ijmm.2013.02.009

Daniels, N. A. (2011). Vibrio vulnificus oysters: pearls and perils. Clin. Infect. Dis. 52, 788-792. doi: 10.1093/cid/ciq251

Das, B., Verma, J., Kumar, P., Ghosh, A., and Ramamurthy, T. (2020). Antibiotic resistance in Vibrio cholerae: understanding the ecology of resistance genes and mechanisms. Vaccine 38, A83-A92. doi: 10.1016/j.vaccine.2019.06.031 
Davies, J., and Davies, D. (2010). Origins and evolution of antibiotic resistance. Microbiol. Mol. Biol. Rev. 74, 417-433. doi: 10.1128/mmbr.00016-10

D'Costa, V., and Wright, G. D. (2009). Biochemical logic of antibiotic inactivation and modification. In: Mayers D. L. (ed). Antimicrobial Drug Resistance. Infectious Disease. New York, USA: Humana Press, 81-95.

de Castillo, M. C., de Allori, C. G., de Gutierrez, R. C., de Saab, O. A, de Fernández, N. P, de Ruiz, C. S. et al. (1998). Action against Vibrio cholerae O1 toxof chemical products used in the lemon production. Rev. Latinoam. Microbiol. 40, 120-123.

De Melo, L.M., Almeida, D., Hofer, E., Dos Reis, C. M., Theophilo, G. N., and Santos, A. F. et al. (2011). Antibiotic resistance of Vibrio parahaemolyticus isolated from pond-reared Litopenaeusvannamei marketed in natal, Brazil. Braz. J. Microbiol. 42, 1463-1469.

Dechet, A. M., Yu PA, Koram N, and Painter J. (2008). Non-food borne Vibrio infections: an important cause of morbidity and mortality in the United States, 1997-2006. Clin. Infect. Dis. 46, 970-976. doi: 10.1086/529148

Delcour, A. H. (2009). Outer membrane permeability and antibiotic resistance. Biochim. Biophys. Acta. 1794, 808-816. doi: 10.1016/j.bbapap.2008.11.005

Deng Y, Xu L, Chen H, Liu S, Guo Z, Cheng C, Ma H, Feng J. et al. (2020). Prevalence, virulence genes, and antimicrobial resistance of Vibrio species isolated from diseased marine fish in South China. Sci. Rep. 10:4329 doi: 10. 1038/s41598-020-71288-0

Dengo-Baloi, L. C., Sem‡-Baltazar, C. A., Manhique, L. V., Chitio, J. E., Inguane, D. L., and Langa, J. P. (2017). Antibiotics resistance in El Tor Vibrio choleraeO1 isolated during cholera outbreaks in Mozambique from 2012 to 2015. PLoS One 12:e0181496. doi: 10.1371/journal.pone.0181496

DrugBank database. Telithromycin (2019). https://go.drugbank.com/drugs/ DB00976 (Accessed: 12 January 2021).

Dwidar, M., Monnappa, A. K., and Mitchell, R. J. (2012). The dual probiotic and antibiotic nature of Bdellovibrio bacteriovorus. BMB Rep. 45, 71-78. doi: 10.5483/bmbrep.2012.45.2.71

Elexson, N., Afsah-Hejri, L., Rukayadi, Y., Soopna, P., Lee, H. Y., Zainazor, T. C. T. et al., (2014). Effect of detergents as antibacterial agents on biofilm of antibiotics-resistant Vibrio parahaemolyticus isolates. Food Control 35, 378-385. doi: 10.1016/J.FOODCONT.2013.07.020

Elmahdi, S., DaSilva, L. V., and Parveen, S. (2016). Antibiotic resistance of Vibrio parahaemolyticus and Vibrio vulnificus in various countries: A review. Food Microbiol. 57, 128-134. doi: 10.1016/j.fm.2016.02.008

Faja, O. M., Sharad, A. A., Younis, K. M., Alwan, M. G., Mohammed, B. J., and Ahmad, A. (2019). Isolation, detection of virulence genes, antibiotic resistance genes, plasmid profile, and molecular typing among Vibrio parahaemolyticus isolated in Malaysian seawater from recreational beaches and fish. Vet. World 12, 1140-1149. doi: 10.14202/vetworld.2019.1140-1149

Founou LL, Founou RC, Essack SY (2016). Antibiotic resistance in the food chain: a developing country-perspective. Front. Microbiol. 7:1881. doi: 10.3389/fmicb. 2016.01881

García-Aljaro, C., Riera-Heredia, J., and Blanch, A. R. (2014). Antimicrobial resistance and presence of the SXT mobile element in Vibrio spp. isolated from aquaculture facilities. New Microbiol. 37, 339-346.

Guijarro, J. A., Cascales, D., García-Torrico, A. I., García-Domínguez, M. and Méndez, J. (2015). Temperature-dependent expression of virulence genes in fish-pathogenic bacteria. Front. Microbiol. 6:700. doi: 10.3389/fmicb.2015. 00700

Han, F., Walker, R. D., Janes, M. E., Prinyawiwatkul, W., and Ge, B. (2007). Antimicrobial susceptibilities of Vibrio parahaemolyticus and Vibrio vulnificus isolates from louisiana gulf and retail raw oysters. Appl. Environ. Microbiol. 73, 7096-7098. doi: 10.1128/aem.01116-07

Higgins, C. F. (2007). Multiple molecular mechanisms for multidrug resistance transporters. Nature 446, 749-757. doi: 10.1038/nature05630

Hill, W. E., Keasler SP, Trucksess MW, Feng P, Kaysner CA, Lampel KA. et al. (1991). Polymerase chain reaction identification of Vibrio vulnificus in artificially contaminated oysters. Appl. Environ. Microbiol. 57, 707-711.

Holmes, A. H., Moore, L. S. P., Sundsfjord, A., Steinbakk, M., Regmi, S., Karkey, A., et al. (2016). Understanding the mechanisms and drivers of antimicrobial resistance. Lancet 387,176-187. doi: 10.1016/s0140-6736(15)00473-0

Hsiao, A., Ahmed, A. M., Subramanian, S., Griffin, N. W., Drewry, L. L., Petri, W. A. Jr., et al. (2014). Members of the human gut microbiota involved in recovery from Vibrio cholerae infection. Nature 515, 423-426. doi: 10.1038/ nature 13738
Hubbard, T. P., Chao, M. C., Abel, S., Blondel, C. J., Wiesch, P. A., Zhou, X. et al. (2016). Genetic analysis of Vibrio parahaemolyticus intestinal colonization. Proc. Natl. Acad. Sci. U.S.A. 113, 6283-6288. doi: 10.1073/pnas.1601718113

Hughes, D., and Karlen, A. (2014). Discovery and preclinical development of new antibiotics. UPS. J. Med. Sci. 119, 162-169. doi: 10.3109/03009734.2014.896437

Jeamsripong, S., Khant, W., and Chuanchuen, R. (2020). Distribution of phenotypic and genotypic antimicrobial resistance and virulence genes in Vibrio parahaemolyticus isolated from cultivated oysters and estuarine water. FEMS Microbiol. Ecol. 96:fiaa081. doi: 10.1093/femsec/fiaa081

Ji, H., Chen, Y., Guo, Y., Liu, X., Wen, J., and Liu, H. (2011). Occurrence and characteristics of Vibrio vulnificus in retail marine shrimp in China. Food Control 22, 1935-1940. doi: 10.1016/J.FOODCONT.2011.05.006

Jiang, X., Ellabaan, M. M. H., Charusanti, P., Munck, C., Blin, K., Tong, Y., et al. (2017). Dissemination of antibiotic resistance genes from antibiotic producers to pathogens. Nat. Commun. 8:15784. doi: 10.1038/ncomms15784

Jones, M.K., and Oliver, J.D. (2009). Vibrio vulnificus: disease and pathogenesis. Infect. Immun. 77, 1723-1733.

Jun, J. W., Shin, T. H., Kim, J. H., Shin, S. P., Han, J. E., Heo, G. J. et al. (2014). Bacteriophage therapy of a Vibrio parahaemolyticus infection caused by a multiple-antibiotic-resistant O3: K6 pandemic clinical strain. J. Infect. Dis. 210, 72-78. doi: 10.1093/infdis/jiu059

Kaas, R. S., Ngandjio, A., Nzouankeu, A., Siriphap, A., Fonkoua, M. C., and Aarestrup, F. M. (2016). The lake chad basin, an isolated and persistent reservoir of Vibrio cholerae O1: A genomic insight into the outbreak in Cameroon, 2010. PLoS One 11:e0155691. doi: 10.1371/journal.pone.0155691

Kim, J. H., Choresca Jr, C. H., Shin, S. P., Han, J. E., Jun, J. W., and Park, S. C. (2011). Occurrence and antibiotic resistance of Vibrio vulnificus in seafood and environmental waters in Korea. J. Food Saf. 31, 518-524. doi: 10.1111/j.17454565.2011.00329.x

Kumar, P., Bag, S., Ghosh, T. S., Dey, P., Dayal, M., Saha, B. et al. (2017). Molecular insights into antimicrobial resistance traits of multidrug resistant enteric pathogens isolated from India. Sci. Rep. 7:14468. doi: 10.1038/s41598017-14791-1

Langley, G., Besser, J., Iwamoto, M., Lessa, F. C., Cronquist, A., Skoff, T. H., et al. (2015). Effect of culture-independent diagnostic tests on future emerging infections program surveillance. Emerg. Infect. Dis. 21, 1582-1588. doi: 10.3201/ eid2109.150570

Lepuschitz, S., Baron, S., Larvor, E., Granier, S. A., Pretzer, C., Mach, R. L., et al. (2019). Phenotypic and genotypic antimicrobial resistance traits of Vibrio cholerae non-O1/non-O139 isolated from a large austrian lake frequently associated with cases of human infection. Front. Microbiol. 10:2600. doi: 10. 3389/fmicb.2019.02600

Lindenbaum, J., Greenough, W. B., and Islam, M. R. (1967). Antibiotic therapy of cholera in children. Bull. World Health Organ. 37, 529-538.

Liu JW, Lee IK, Tang HJ, Ko WC, Lee HC, Liu YC, Hsueh PR, Chuang YC. (2006). Prognostic factors and antibiotics in Vibrio vulnificus septicemia. Arch. Inter. Med. 166, 2117-2123.

Lyon, W. J. (2001). TaqMan PCR for detection of Vibrio cholerae O1, O139, non$\mathrm{O} 1$, and non-O139 in pure cultures, raw oysters, and synthetic seawater. Appl. Environ. Microbiol. 67, 4685-4693.

Macwan, S.R., Dabhi, B. K., Aparnathi, K. D., and Prajapati, J. B. (2016). Essential oils of herbs and spices: their antimicrobial activity and application in preservation of food. Int. J. Curr. Microbiol. App. Sci. 5, 885-901. doi: 10. 20546/IJCMAS.2016.505.092

Mala, W., Alam, M., Angkititrakul, S., Wongwajana, S., Lulitanond, V., Huttayananont, S., et al. (2016). Serogroup, virulence, and molecular traits of Vibrio parahaemolyticus isolated from clinical and cockle sources in northeastern Thailand. Infect. Genet. Evol. 39, 212-218. doi: 10.1016/j.meegid. 2016.01.006

Mariya Sony, Sumithra, T.G., Anushree, V.N., Amalab, P. V., Reshma, K. J., Swapna, A., Sanil, N. K. et al (2021). Antimicrobial resistance and virulence characteristics of Vibrio vulnificus, Vibrio parahaemolyticus and Vibrio harveyi from natural disease outbreaks of marine/estuarine fishes. Aquaculture. 539:736608. doi: 10.1016/j.aquaculture.2021.7 36608

Martin, S., Lopez, A. L., Bellos, A., Deen, J., Ali, M., Alberti, K., et al. (2014). Postlicensure deployment of oral cholera vaccines: a systematic review. Bull. World Health Organ. 92, 881-893. doi: 10.2471\%2FBLT.14.139949 
Mata, L., Vargas, C., Saborio, D., and Vives, M. (1994). Extinction of Vibrio cholerae in acidic substrata: contaminated cabbage and lettuce treated with lime juice. Rev. Biol. Trop. 42, 487-492.

Mazel, D., and Davies, J. (1999). Antibiotic resistance in microbes. Cell Mol. Life Sci. 56, 742-754. doi: 10.1007/s000180050021

Meibom, K. L., Blokesch, M., Dolganov, N. A., Wu, C. Y., and Schoolnik, G. K. (2005). Chitin induces natural competence in Vibrio cholerae. Science. 310, 1824-1827. doi: 10.1126/science.1120096

Morita, D., Takahashi, E., Morita, M., Ohnishi, M., Mizuno, T., and Miyoshi, S. I. (2020). Genomic characterization of antibiotic resistance-encoding genes in clinical isolates of Vibrio cholerae non-O1/non-O139 strains from Kolkata, India: generation of novel types of genomic islands containing plural antibiotic resistance genes. Microbiol. Immunol. 64, 435-444. doi: 10.1111/1348-0421. 12790

Morris, J.G. Jr, and Tenney, J. (1985). Antibiotic therapy for Vibrio vulnificus infection. J. Am. Med. Assoc. 253, 1121-1122. doi: 10.1001/jama.1985. 03350320041011

Newton A, Kendall M, Vugia DJ, Henao OL, Mahon BE. (2012). Increasing rates of vibriosis in the United States, 1996-2010: review of surveillance data from 2 systems. Clin. Infect. Dis. 54, 391-395.

Nordstrom, J. L., Vickery, M. C. L., Blackstone, G. M., Murray, S. L., and DePaola, A. (2007). Development of a multiplex real-time PCR assay with an internal amplification control for the detection of total and pathogenic Vibrio parahaemolyticus bacteria in oysters. Appl. Environ. Microbiol. 73, 5840-5847.

Okoh, A. I., and Igbinosa, E. O. (2010). Antibiotic susceptibility profiles of some Vibrio strains isolated from wastewater final effluents in a rural community of the eastern cape province of south africa. BMC Microbiol. 10:143. doi: 10.1186/ 1471-2180-10-143

Oliver, J. D. (2006). Vibrio vulnificus. In Biology of Vibrios. eds F. L. Thompson, B. Austin, and J. Swing (Washington, DC: ASM Press), 349-366.

Oyelade, A. A., Adelowo, O. O., and Fagade, O. E. (2018). bla ${ }_{N D M-1}$-producing Vibrio parahaemolyticus and V. vulnificus isolated from recreational beaches in Lagos, Nigeria. Environ. Sci. Pollut. Res. 25, 33538-33547. doi: 10.1007/s11356018-3306-2

Pan, J. H., Zhang, Y. J., Jin, D. Z., Ding, G. Q., Luo, Y., Zhang, J. Y., et al. (2012). Molecular characterization and antibiotic susceptibility of Vibrio vulnificus in retail shrimps in Hangzhou, People's Republic of China. J. Food Prot. 76, 2063-2068. doi: 10.4315/0362-028X.JFP-13-161

Partridge, S. R., Kwong, S. M., Firth, N., Jensen, S. O. (2018). Mobile genetic elements associated with antimicrobial resistance. Clin. Microbiol. Rev. 31:e0088-17. doi: 10.1128/cmr.00088-17

Parvin, I., Shahunja, K. M., Khan, S. H., Alam, T., Shahrin, L., Ackhter, M. M., et al. (2020). Changing Susceptibility Pattern of Vibrio cholerae O1 Isolates to Commonly Used Antibiotics in the Largest Diarrheal Disease Hospital in Bangladesh during 2000-2018. Am. J. Trop. Med. Hyg. 103, 652-658. doi: 10. 4269/ajtmh.20-0058

Pascale, G. D., and Wright, G. D. (2010). Antibiotic resistance by enzyme inactivation: from mechanisms to solutions. ChemBioChem. 11, 1325-1334. doi: 10.1002/cbic.201000067

Passalacqua, P. L., Zavatta, E., Bignami, G., Serraino, A., and Serratore, P. (2016). Occurrence of Vibrio parahaemolyticus, Vibrio cholerae and Vibrio vulnificus in the Clam RuditapesPhilippinarum (Adams \& Reeve, 1850) from Emilia Romagna and Sardinia, Italy. Ital. J. Food Saf. 5:5709. doi: 10.4081/ijfs.2016. 5709

Popovic, T., Olsvik, O., Blake, P. A., and Wachsmuth, K. (1993). Cholera in the Americas: foodborne aspects. J. Food Prot. 56, 811-821. doi: 10.4315/0362028x-56.9.811

Prokocimer, P., Bien, P., DeAnda, C., Pillar, C. M., and Bartizal, K. (2012). In vitro activity and microbiological efficacy of Tedizolid (TR-700) against Gram-positive clinical isolates from a phase 2 study of oral Tedizolid phosphate (TR-701) in patients with complicated skin and skin structure infections. Antimicrob. Agents Chemother. 56, 4608-4613. doi: 10.1128/aac.00458-12

Ramamurthy, T., Das, B., Chakraborty, S., Mukhopadhyay, A. K., and Sack, D. A. (2020). Diagnostic techniques for rapid detection of Vibrio cholerae O1/O139. Vaccine. 38, A73-A82. doi: 10.1016/j.vaccine.2019.07.099

Rapa, R. A., amd Labbate, M. (2013). The function of integron-associated genes cassettes in Vibrio species: the tip of the iceberg. Front. Microbiol. 4:385. doi: $10.3389 /$ fmicb. 2013.00385
Reimann, H. A., and Chang, G. C. (1946).Asiatic cholera; clinical study and experimental therapy with streptomycin. Am. J. Trop. Med. Hyg. 26, 631-647. doi: 10.4269/ajtmh.1946.s1-26.631

Saha, D., Karim, M. M., Khan, W. A., Ahmed, S., Salam, M. A., and Bennish, M. L. (2006). Single-dose azithromycin for the treatment of cholera in adults. N. Engl. J. Med. 354, 2452-2462. doi: 10.1056/NEJMoa054493

Scallan E, Hoekstra RM, Angulo FJ, Tauxe RV, Widdowson MA, Roy SL. et al. (2011). Foodborne illness acquired in the United States-major pathogens. Emerg. Infect. Dis. 17, 7-15.

Shea, S., Kubota, K. A., Maguire, H., Gladbach, S., Woron, A., Atkinson-Dunn, R., et al. (2016). Clinical microbiology laboratories' adoption of cultureindependent diagnostic tests is a threat to foodborne-disease surveillance in the United States. J. Clin. Microbiol. 55, 10-19. doi: 10.1128/JCM. 01624-16

Singh, S., Singh, S. K., Chowdhury, I., Singh, R. (2017). Understanding the mechanism of bacterial biofilms resistance to antimicrobial agents. Open Microbiol. J. 11, 53-62. doi: 10.2174/1874285801711010053

Sinha-Ray, S., Alam, M. T., Bag, S., Morris, J. G. Jr., and Ali, A. (2019). Conversion of a recA-mediated Non-toxigenic Vibrio cholerae O1 Strain to a toxigenic strain using chitin-induced transformation. Front. Microbiol. 10:2562. doi: 10.3389/ fmicb.2019.02562

Soucy, S. M., Huang, J., Gogarten, J. P. (2015). Horizontal gene transfer: building the web of life. Nat. Rev. Genet. 16, 472-482. doi: 10.1038/nrg3962

Sudha, S., Mridula, C., Silvester, R., and Hatha, A. A., (2014). Prevalence and antibiotic resistance of pathogenic vibrios in shellfishes from Cochin market. Indian J. Geo. Mar. Sci. 43, 815-824.

Sun, H., Zhang, Q., Wang, R., Wang, H., Wong Y. T., Wang, M. et al. (2020). Resensitizing carbapenem- and colistin-resistant bacteria to antibiotics using auranofin. Nat. Commun. 11:5263. doi: 10.1038/s41467-02018939-y

Sun, J., Deng, Z., and Yan, A. (2014). Bacterial multidrug efflux pumps: mechanisms, physiology and pharmacological exploitations. Biochem. Biophys. Res. Commun. 453, 254-267. doi: 10.1016/j.bbrc.2014.05.090

Tan, C. W., Rukayadi, Y., Hasan, H., Thung, T. Y., Lee, E., Rollon, W. D. et al. (2020). Prevalence and antibiotic resistance patterns of Vibrio parahaemolyticus isolated from different types of seafood in Selangor, Malaysia. Saudi J. Biol. Sci. 27, 1602-1608. doi: 10.1016/j.sjbs.2020.01.002

Tang, H. J., Chang, M. C., Ko, W. C., Huang, K. Y., Lee, C. L., and Chuang, Y. C. (2002). In vitro and in vivo activities of newer fluoroquinolones against Vibrio vulnificus. Antimicrob. Agents Chemother. 46, 3580-3584. doi: 10.1128/aac.46. 11.3580-3584.2002

Tarr, G. A. M., Chui, L., Lee, B. E., Pang, X. L., Ali, S., Nettel-Aguirre, A., et al. (2019). Performance of stool-testing recommendations for acute gastroenteritis when used to identify children with 9 potential bacterial enteropathogens. Clin. Infect. Dis. 69, 1173-1182. doi: 10.1093/cid/ ciy1021

Upadhyay, A., Mooyottu, A., Yin, H., Nair, M. S., Bhattaram, V., and Venkitanarayanan, K. (2015). Inhibiting microbial toxins using plant-derived compounds and plant extracts. Medicines 2, 186-211.

Uylangco, C. V., Fabie, A. E., Mier, S. G., and Santiago, L. (1965). Oral streptomycin in the treatment of cholera. J. Philipp. Med. Assoc. 41, 763-769.

Verma, J., Bag, S., Saha, B., Kumar, P., Ghosh, T. S., Dayal, M. et al. (2019). Genomic Plasticity associated with the antimicrobial resistance in Vibrio cholerae. Proc. Natl. Acad. Sci. USA. 116, 6226-6231. doi: 10.1073/pnas.19001 41116

von Wintersdorff, C. J. H., Penders, J., van Niekerk, J. M., Mills, N. D., Majumder, S., van Alphen, L. B., et al. (2016). Dissemination of antimicrobial resistance in microbial ecosystems through horizontal gene transfer. Front. Microbiol. 7:173. doi: $10.3389 /$ fmicb.2016.00173

World Health Organization. (2015). Global Antimicrobial Resistance Surveillance System: Manual For Early Implementation. Geneva: WHO Press.

Wozniak, R. A., and Waldor, M. K. (2010). Integrative and conjugative elements: mosaic mobile genetic elements enabling dynamic lateral gene flow. Nat. Rev. Microbiol. 8, 552-563. doi: 10.1038/nrmicr o2382

Wyk, H. V. (2015). Antibiotic resistance. South Afr. Pharma. J. 82, 20-23.

Yano, Y., Hamano, K., Satomi, M., Tsutsui, I., and Aue-umneoy, D. (2011). Diversity and characterization of oxytetracycline-resistant bacteria associated 
with non- native species, white-leg shrimp (Litopenaeusvannamei), and native species, black tiger shrimp (Penaeus monodon), intensively cultured in Thailand. J. Appl. Microbiol. 110, 713-722. doi: 10.1111/j.1365-2672.2010. 04926.x

Yaraksa, N., Anunthawan, T., Theansungnoen, T., Daduang, S., Araki, T., Dhiravisit, A. et al. (2014). Design and synthesis of cationic antibacterial peptide based on Leucrocin I sequence, antibacterial peptide from crocodile (Crocodylus siamensis) white blood cell extracts. J. Antibiot. 67, 205-212. doi: 10.1038/ja.2013.114

Zanetti, S., Spanu, T., Deriu, A., Romano, L., Sechi, L. A., and Fadda, G. (2001). In vitro susceptibility of Vibrio spp. isolated from the environment. Int. J. Antimicrob. Agents 17, 407-409. doi: 10.1016/s0924-8579(01) 00307-7
Conflict of Interest: SB was employed by company: 3B BlackBio Biotech India Limited.

The remaining authors declare that the research was conducted in the absence of any commercial or financial relationships that could be construed as a potential conflict of interest.

Copyright (๑) 2021 Dutta, Kaushik, Kumar and Bag. This is an open-access article distributed under the terms of the Creative Commons Attribution License (CC BY).

The use, distribution or reproduction in other forums is permitted, provided the original author(s) and the copyright owner(s) are credited and that the original publication in this journal is cited, in accordance with accepted academic practice. No use, distribution or reproduction is permitted which does not comply with these terms. 